\title{
Unconvincing Evidence That Rats Show a Mozart Effect
}

Kenneth M. Steele

Appalachian State University

F. H. RAUSCHER, J. D. ROBINSON, AND J. J. JENS (1998) REPORTED that rats learned to complete a T-maze more quickly if they had been reared listening to a Mozart piano sonata. They interpreted this result as a demonstration of a "Mozart effect" in rats. Steele (2003) compared rat and human audiograms, in the context of piano note frequencies, and suggested that rats were deaf to most of the notes (69\%) in the sonata. Steele concluded that the learning differences among the groups were not due to a Mozart effect. Rauscher (2006) argued for the use of a different rat audiogram which would increase the number of notes potentially heard to $57 \%$. This is not a refutation of Steele's conclusion that rats would not hear major portions of the sonata. These missing portions will deform the music structure heard by the rats. Whatever the rats hear, it is not the sonata written by Mozart. Additional comments are made about the current status of the Mozart-effect literature with human subjects.

Received February 16, 2006, accepted April 4, 2006

I THANK THE EDITORS OF MUSIC PERCEPTION for the opportunity to comment on Rauscher's (2006) reply to my answer of whether rats showed a Mozart effect in the Rauscher, Robinson, and Jens (1998) study. The conclusion of Steele (2003) was that rats did not show a Mozart effect because they were deaf to the majority of notes in the sonata. Rauscher has presented the possibility that the rats heard more notes than were calculated in Steele (2003). Even if Rauscher is correct, rats are still deaf to major portions of the sonata. The portions that would be heard would have a distorted music structure. Whatever is heard by rats is not a Mozart piano sonata. I will comment on three issues raised in Rauscher's response: (a) the discrepancy in note counts between Rauscher and Steele (2003); (b) the issue of what rats hear when music is played; and (c) the status of the Mozart effect in humans. I end with a comment on the general issue of replication of results.

\section{The Note Count Issue}

Rauscher reported that her absolute note count differed from mine and speculated that the difference may be due to my missing a repeat sign in the score. She concluded that the discrepancy was inconsequential because it did not alter the proportional distribution of notes. Rauscher was correct that my absolute count values were too low and that it was related to the repeat-sign issue. Table 1 shows a corrected table of values.

Table 1 shows the proportions of notes above C5 for different sections of the score. One count is for notes through the 80th measure, which is where a single repeat instruction occurs in the Hughes (1926) score. Another count shows the distribution of notes, excluding the first 80 measures. Finally there is a count of the entire section both with and without the repeated section. We had done all permutations of the count originally because the repeat sign in our score had been crossed out and "no repeat" had been written above the sign. It took time to determine whether the inscription referred to a mistake, a commonly ignored instruction, or some other intention. At some point during the manuscript preparation, the absolute values for the repeat section alone replaced the absolute values for the section including the repeat. However, the values in Table 1 show that the proportional values remain almost constant across the various permutations. The general arguments of Steele (2003) are not affected by the change in the absolute count of notes.

(There is not complete agreement since she reports a second repeat instruction, which does not appear in my score either as :| or as DS or DC. Also, her count of notes in the lowest octave is higher than mine. My Figure 4 indicated a small percentage of notes occurred in that octave, not zero.)

\section{Thresholds and the Issue of Hearing Limits}

Figure 1 shows the comparison between a typical rat audiogram (Heffner, Heffner, Contos, \& Ott, 1994) and a human audiogram (Jackson, Heffner, \& Heffner, 1999). The first point is to notice how different the hearing ranges of rats and people are. Rats hear sounds

Music Perception volume 23, ISSUe 5, PP. 455-458, ISSN 0730-7829, ELECTRONIC ISSN 1533-8312 @ 2006 By THE REgENTS OF THE UNIVERSITY OF CALIFORNIA. ALL RIGHTS RESERVED. PLEASE DIRECT ALL REQUESTS FOR PERMISSION TO PHOTOCOPY OR REPRODUCE ARTICLE CONTENT THROUGH THE UNIVERSITY OF CALIFORNIA PRESS'S RIGHTS AND PERMISSIONS WEBSITE AT WWW.UCPRESS.EDU/JOURNALS/RIGHTS.HTM 
TABLE 1. Proportion of musical notes above C5 in the K. 448 Sonata (Hughes, 1926).

\begin{tabular}{lccc}
\hline & \multicolumn{3}{c}{ Count } \\
\cline { 2 - 4 } Section & Above C5 & Total & Percent \\
\hline Measures 1-80 & 870 & 2790 & 31.1 \\
Measures 81-194 & 1284 & 3766 & 34.1 \\
$\begin{array}{l}\text { Measures 1-194 } \\
\text { Measures 1-194 }\end{array}$ & 2154 & 6556 & 32.9 \\
(with repeat) & 3024 & 9346 & 32.4 \\
\hline
\end{tabular}

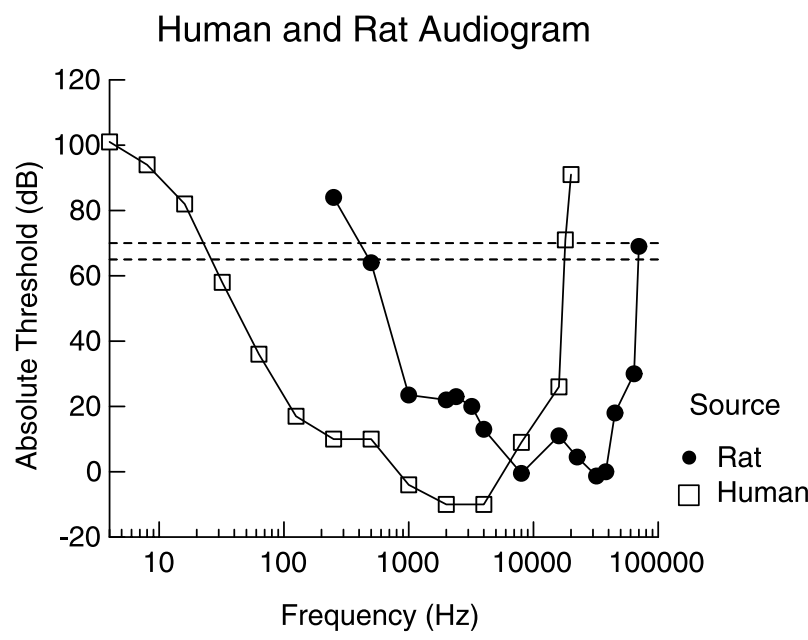

FIG. 1. Relationship between human audiogram and rat audiogram. Stimulus intensity was measured in $\mathrm{dB}$ SPL and frequency was measured in $\mathrm{Hz}$ and is reported on a log scale. Greater sensitivity is indicated by lower threshold values. The human results (unfilled squares) are from Jackson, Heffner, and Heffner (1999) and

the rat results (filled circles) are from Heffner, Heffner, Contos, and Ott (1994). The dashed lines indicate the range of amplitudes reported in Rauscher et al. (1998).

of $30 \mathrm{KHz}$ easily, well outside the range of humans, but rats show a quick decline in sensitivity for frequencies below $1000 \mathrm{~Hz}$. Rat hearing did not evolve to listen to human-created musical instruments.

The dashed lines indicate the range of sound intensities reported in Rauscher et al. (1998). Data points above the lines indicate frequency values that would require a higher intensity than was presented in the Rauscher et al. experiment to be above absolute threshold. These frequencies would not be heard at the sound intensity used in the Rauscher et al. experiment. Steele (2003) argued that the dashed lines intersect the rat audiogram at approximately $500 \mathrm{~Hz}$ and suggested that frequencies below $500 \mathrm{~Hz}$ (located approximately at C5 on the piano) were below absolute threshold for the rats. The values in Table 1 indicate that the rats would have only heard about one-third of the sonata according to this calculation.

Rauscher substituted a study by Kelly and Masterton (1977) that reported the absolute threshold for their rats at $250 \mathrm{~Hz}$ was $70 \mathrm{~dB}(\mathrm{SPL})$ rather than the $84 \mathrm{~dB}$ value in Figure 1. Rauscher argued this new cutoff would drop the absolute threshold arguably by about an octave so that the rats potentially could have heard $57 \%$ of the notes in the sonata. Kelly and Masterton's results for $250 \mathrm{~Hz}$ were not typical; most studies did not even test for hearing below $500 \mathrm{~Hz}$ (Fay, 1988). Even if one accepts the Kelly and Masterton substitution, it is not clear that hearing $57 \%$ of the notes is a refutation of my conclusion that a major portion of the sonata could not be heard by the rats.

An audiogram in a psychophysical study is obtained under very quiet conditions and represents a best-case result for hearing sensitivity. Thresholds will be higher outside of that situation due to the presence of background noise. Rauscher reported that her ventilation fan was so quiet that it did not register on her sound meter. The fan would need to be very quiet. Blake and Sekuler (2006) report that the sound of normal breathing is $10 \mathrm{~dB}$ SPL in amplitude, and my ventilation system produced a reading of $50 \mathrm{~dB}$ SPL in the quietest room I could find on the hallway.

The practical question is what sound intensities demarcate the boundaries of ordinary hearing sensitivity. Heffner and Heffner $(1998,2003)$ use $60 \mathrm{~dB}$ as their criterion. A sound is outside the range of hearing if its absolute threshold value is above $60 \mathrm{~dB}$; this would correspond to about $500 \mathrm{~Hz}$ in both Kelly and Masterton (1977) and Heffner et al. (1994). This criterion is applied explicitly to the case of comparing music perception across species. Heffner and Heffner (2003) state:

One such case is a series of studies which concluded that laboratory rats were superior to cebus monkeys in discriminating melodies (D’Amato, 1988). However, inspection of the auditory stimuli reveals that some of the melodies contained frequencies below $500 \mathrm{~Hz}$, which, while clearly audible to monkeys, are beyond the hearing range of rats. As a result, the monkeys had to discriminate between two clearly audible, but different tunes, whereas the rats had to discriminate between a tune they could hear well and one that contained many inaudible notes. Thus, the results of this study are more likely a demonstration of sensory, rather than cognitive differences between monkeys and rats. Clearly, it is important not to assume that what is audible to one species is equally as audible to another. (pp. 426-427) 
This quotation makes clear a second problem with the unheard notes. The rats were being exposed to a sequence of sounds that have a different music structure than the ones heard by the cebus monkeys. Rauscher may be correct that other musical values are of interest but "melodic contour, the rhythmic or temporal pattern of the notes, the ratio of filled to unfilled durations, timbre, harmonic relationships, intervallic relationships" are all going to be affected if the rats cannot hear half of the notes.

Rauscher's mention of intervallic relationships brings up a second problem in understanding what a rat hears when music is played. Successive notes increase in frequency by approximately $5.9 \%$ as one ascends the piano scale (Reblitz, 1976). The difference between two successive notes is readily detected by humans because our Weber fraction for frequency changes is only $0.2 \%$ (Yost, 2000). Rats are much poorer at frequency discriminations. Syka, Rybalko, Brožek, and Jilek (1996) reported that the mean Weber fraction for frequency discrimination with pigmented rats was 5.7\% $(+/-$ 1.5\%). Talwar and Gerstein (1999) reported that the Weber fraction was $6.25 \%(+/-0.23 \%)$ for their rat subjects. If these data, obtained with pure tones, hold for the discrimination of piano tones in rats, then it is a very questionable assumption that rats will hear and map an octave into 12 equal intervals like humans and maintain these interval relationships across octaves.

\section{The Mozart Effect in Humans}

Rauscher repeats her standard explanations of why other labs fail to produce a Mozart effect. The first explanation was that other labs were using the wrong dependent measure. Fudin and Lembessis (2004) have traced the history of this explanation and documented its post hoc nature. Rauscher et al. (1993) used three tasks from the Stanford-Binet IQ measure: Matrices, Pattern Analysis, Paper Folding and Cutting. The results of these independently scored tasks were combined into a spatial reasoning score. Early failed attempts to replicate the Mozart effect used tasks very similar to the Matrices and Pattern Analysis measures. For example, Newman, Rosenbach, Burns, Latimer, Matocha, and Vogt (1995) and Stough, Kerkin, Bates, and Mangan (1994) used the Ravens Advanced Progressive Matrices task. Neither study found a Mozart effect. Rauscher and Shaw (1998) reported that a reanalysis of their 1993 results indicated that the Mozart effect was found only with the Paper Folding and Cutting task. Therefore, the failure by Newman et al. and Stough et al. to find a Mozart effect with a Matrices task was "not surprising" because they had used the wrong dependent measure. The experiments of interest to Music Perception readers were reported after 1998 and all have used Rauscher's dependent measure, the Paper Folding and Cutting task (e.g., Nantais \& Schellenberg, 1999; Steele, Bass, \& Crook, 1999; Steele, Dalla Bella, Peretz, Dunlop, Dawe, Humphrey, et al., 1999).

Rauscher's second explanation for the failures that cannot be explained by use of the wrong music or wrong dependent measure is to tie them to a specific laboratory-mine. There are two problems with this explanation. It is not just my lab; other laboratories have failed to replicate the effect. For example, the Steele, Dalla Bella, et al. (1999) report combines results from work independently conducted at three different universities: Appalachian State University, University of Montreal, and University of Western Ontario. Second, there is a "lab effect" in the Mozart-effect literature, but it is Rauscher's lab. The Hetland (2000, p. 134) meta-analysis identified Rauscher's lab as reporting significantly greater effect-sizes than other labs. Hetland's metaanalysis did not test whether there was a Steele-lab effect because she "could not identify consistent or obvious procedures that might cause systematic differences in results, and because his results, although consistently lower than average, appear to fall within the normal range on the stem and leaf display" (p. 145). Rauscher's problem with my studies is that there can be no appeal to a wrong music/wrong dependent measure explanation.

I criticized the Hetland (2000) meta-analysis because it included more than 600 subjects from unpublished work by Rauscher. The identification of the Rauscher-lab effect should have made Hetland hesitant about the inclusion of these results. In addition, these unpublished results were given extra weight in the Hetland meta-analysis because "experimenter expectancy" effects were reduced. This is Rauscher's newest explanation of why other studies fail to find a Mozart effect, a failure to control for experimenter expectancy. It is difficult to evaluate this explanation because the studies remain unpublished and the method used to reduce experimenter expectancy effects is unknown. If experimenter expectancy was the critical factor, then I should have replicated her results. I began my work expecting to produce the effect. It took several experiments before I began to question the existence of the effect.

\section{The Replication Issue}

Rauscher concludes her reply by describing another unpublished rat study in which both a Mozart effect was obtained and its genetic basis was described. I do not 
count this report as a replication. The issue is whether independent laboratories, staffed by individuals without personal investment in a specific outcome, can reliably produce an effect. The Mozart effect in rats is still in need of replication and, as argued in Steele (2003), explanation.

\section{Author Note}

Address correspondence to: to K. M. Steele, Department of Psychology, Appalachian State University, Boone, NC 28608. E-MAIL steelekm@appstate.edu

\section{References}

Blake, R., \& Sekuler, R. (2006). Perception (5th ed.). New York: McGraw-Hill.

D’Amato, M. R. (1988). A search for tonal pattern perception in cebus monkeys: Why monkeys can't hum a tune. Music Perception, 5, 453-480.

FAY, R. R. (1988). Hearing in vertebrates: A psychophysics databook. Winnetka, IL: Hill-Fay Associates.

Fudin, R., \& LEMBESSIS, E. (2004). The Mozart effect: Questions about the seminal findings of Rauscher, Shaw, and colleagues. Perceptual and Motor Skills, 98, 389-405.

Heffner, H. E., \& HeFFner, R. S. (1998). Hearing. In G. Greenberg \& M. M. Haraway (Eds.), Comparative psychology: A handbook (pp. 290-303). New York: Garland Press.

Heffner, H. E., \& Heffner, R. S. (2003). Audition. In S. Davis (Ed.), Handbook of research methods in experimental psychology (pp. 413-440). Malden, MA: Blackwell.

Hefrner, H. E., Hefrner, R. S., Contos, C., \& OtT, T. (1994). Audiogram of the hooded Norway rat. Hearing Research, 73, 244-247.

HeTland, L. (2000). Listening to music enhances spatial reasoning: Evidence for the "Mozart effect." Journal of Aesthetic Education, 34, 105-148.

Hughes, E. (1926). Wolfgang Amadeus Mozart: Sonata in D and fugue in C minor for two pianos, four-hands (Vol. 1504). New York: G. Schirmer.

Jackson, L. L., Heffner, R. S., \& Heffner, H. E. (1999). Freefield audiogram of the Japanese macaque (Macca fuscata). Journal of the Acoustical Society of America, 106, 3017-3023.

Kelly, J. B., \& MAsterton, B. (1977). Auditory sensitivity of the albino rat. Journal of Comparative and Physiological Psychology, 91, 930-936.

Nantais, K. M., \& SchellenberG, E. G. (1999). The Mozart effect: An artifact of preference. Psychological Science, 10, 370-373.
Newman, J., Rosenbach, J. H., Burns, K. L., Latimer, B. C., Matocha, H. R., \& VogT, E. E. (1995). An experimental test of "the Mozart effect": Does listening to his music improve spatial ability? Perceptual and Motor Skills, 81, 1379-1387.

RausCher, F. H. (2006). The Mozart effect in rats: Response to Steele. Music Perception, 23, 447-454.

Rauscher, F. H., Robinson, K. D., \& JENS, J. J. (1998). Improved maze learning through early music exposure in rats. Neurological Research, 20, 427-432.

Rauscher, F. H., \& SHAW, G. L. (1998). Key components of the Mozart effect. Perceptual and Motor Skills, 86, 835-841.

Rauscher, F. H., Shaw, G. L., \& Ky, K. N. (1993). Music and spatial task performance. Nature, 365, 611.

Reblitz, A. A. (1976). Piano servicing, tuning, \& rebuilding: For the professional, the student, the hobbyist. Vestal, NY: Vestal Press.

SteEle, K. M. (2003). Do rats show a Mozart effect? Music Perception, 21, 251-265.

Steele, K. M., Bass, K. E., \& Crook, M. D. (1999). The mystery of the Mozart effect: Failure to replicate. Psychological Science, $10,366-369$.

Steele, K. M., Dalla Bella, S., Peretz, I., Dunlop, T., Dawe, L. A., Humphrey, G. K., Shannon, R. A., Kirby, J. L., Jr., \& Olmsted, C. G. (1999). Prelude or requiem for the "Mozart effect"? Nature, 400, 827.

Stough, C., Kerkin, B., Bates, T., \& Mangan, G. (1994). Music and spatial IQ. Personality and Individual Differences, 17, 695.

Syka, J., Rybalko, N., BrožEK, J., \& JileK, M. (1996). Auditory frequency and intensity discrimination in pigmented rats. Hearing Research, 100, 107-113.

TAlWAR, S. K., \& GerSTEIN, G. L. (1999). A signal detection analysis of auditory-frequency discrimination in the rat. Journal of the Acoustical Society of America, 105, 1784-1800.

YosT, W. A. (2000). Fundamentals of hearing: An introduction (4th ed.). San Diego, CA: Academic Press. 